\title{
EXPLICITNESS IN TRANSLATION AND INTERPRETING: A CRITICAL REVIEW AND SOME EMPIRICAL EVIDENCE (OF AN ELUSIVE CONCEPT)
}

\author{
NICOLE BAUMGARTEN ${ }^{1}$, BERND MEYER ${ }^{2}$ AND DEMET ÖZÇETIN ${ }^{3}$ \\ ${ }^{1}$ University of Southern Denmark \\ Department of Business Communication and Information Science \\ Alsion 2, DK-6400 Sønderborg, Phone: +45 6550 1255, Fax: -1092 \\ E-mail: nicole.baumgarten@sitkom.sdu.dk \\ ${ }^{2}$ Research Centre on Multilingualism, University of Hamburg \\ Max Brauer Allee 60, D-22765 Hamburg, Phone: 0049-40-42838-6456, Fax: -6116 \\ E-mail: bernd.meyer@uni-hamburg.de \\ ${ }^{3}$ Research Centre on Multilingualism, University of Hamburg \\ Max Brauer Allee 60, D-22765 Hamburg, Phone: 0049-40-42838-6427, Fax: -6116 \\ E-mail: demet.oezcetin@uni-hamburg.de
}

\begin{abstract}
In this paper, we will try to grasp the elusive and controversial concept of explicitness which has been considered from different perspectives in linguistics and will take a special look at different approaches in translation and interpretation studies. Thereby, the often postulated assumption that explicitness is a universal feature appearing in all kinds and all instances of language mediation will be questioned. We will show that explicitness does not result from the translation or interpreting process per se but that other factors (also) need to be taken into account, especially conventional differences between the languages involved and the different interpreting strategies of the interpreters. Our investigation is based on data from a parallel corpus of German-English popular science texts and a corpus of interpreter-mediated discourse in a conference setting.
\end{abstract}

Keywords: explicitness, explicitation, translation, interpreting, translation universals

\section{EXPLICITNESS AND EXPLICITATION}

\subsection{Explicitness in Linguistics: General Remarks}

In its most basic meaning in the field of linguistics, the term explicitness refers to the overt encoding of information. In other words, the part of a message that is encoded linguistically is explicit, while the information which can be understood from the message without being directly referred to by linguistic material is implicit. Usually, in communicative interaction, only part of what is said is said explicitly, that is, with the lexical and grammatical means of a language. Another part is said implicitly; it is 'said between the lines', i.e., suggested, or presupposed by the speaker/writer. Part of this indirect meaning is 
conventionally associated with lexical and grammatical means - as e.g. in the case of indirect speech acts (Searle 1975) or conventionalized connotations of lexical items; another part of the implicit meaning, however, is unrelated to the linguistic structure of the message and is added on the basis of shared knowledge about the situational context of the communicative exchange and knowledge about the states of affairs referred to (cf. Doherty 2002: 171). It is generally acknowledged that communication functions on the basis of such 'common ground' shared by speaker and hearer (Stalnaker 1978/2002: 151, Clark 1992: 148).

In a cross-linguistic perspective explicitness - in the sense of the amount of information that is overtly linguistically encoded - has been posited as a feature that distinguishes the communicative conventions in different languages (e.g. House 1996, 2003). That is, in some languages messages require more linguistic meaning to be explicitly encoded by linguistic material than in other languages in order to be 'acceptable' in communicative interaction. Comparing English and German written texts and spoken discourses, House (2004) suggests that

... in German discourse as opposed to Anglophone discourse, speakers and writers tend to prefer presenting information in a rather more 'explicit' than 'implicit' manner, i.e. they tend to (overtly) encode or verbalize propositional content rather than leave it to be inferred from the context (House 2004: 186f).

An explanation for this difference in explicitness is provided by language typological approaches within contrastive linguistics, which likewise use "explicitness" as a measure of difference. Explicitness is here posited as a feature that distinguishes the organization of information structure in different languages. The amount of information that has to be explicitly encoded is related to optimal meaning interpretation on sentence level and discoursal/textual coherence. In this approach, the degree of "explicitness" of a message is seen as a reflection of different conventionalized patterns of information processing by language users. For example, German texts/discourses tend to feature more logical connectives, endophoric expressions and focus-marking elements (e.g. discourse particles) than comparable texts in English, even though the omission of the connectives, endophoric expressions and focus elements would not render the German sentence ungrammatical or necessarily lead to a different interpretation of the sentence (Doherty 1995, 2002; Fabricius-Hansen 1999, 2005). In a very simplified manner, this difference between English and German can be explained by differences in information structure on sentence level, where English is characterized by a comparatively fixed word order, which primarily 
denotes grammatical relations (Thompson 1978). In contrast, German has a relatively free word order which allows the expression of pragmatic meanings through topicalization and the incorporation of a high number of lexical and grammatical items into the sentence (Fabricius-Hansen 1998). The 'excess' linguistic material in German has the function of making meanings (which could as well be implicated) explicit in order to secure optimal information processing, i.e., to prevent misunderstanding, to avoid the potential arising of alternative interpretations and to guide the reader/hearer towards the intended interpretation (Doherty 2002; Fabricius-Hansen 2005, 1998, 1999; Behrens 2004). In this sense, a given German text/discourse can be characterized as more explicit than a comparable English text, because the German text/discourse usually features quantitatively more linguistic material.

In text and register linguistics (e.g. Biber 1988; v. Hahn 1996), explicitness is furthermore described as a property of texts and discourses. It is seen as the opposite of context-dependent communication. According to v. Hahn (1996), explicitness results from the need for denotational precision and referential specificity in specific types of communicative interaction such as written communication and risk communication. Explicit texts/discourses are independent of their contexts of text production and reception in the sense that every link to their contexts of text production is unambiguously encoded in the text/discourse. This requires, for example, the use of lexical material with high meaning specificity and full grammatical structures, such as the choice of lexical expressions instead of pronominal reference and the avoidance of elliptical structures. From the perspective of register linguistics, explicitness is predominantly a property of written registers, as it is necessary for written communication that texts are comprehensible in other contexts than their context of text production. In contrast, texts/discourses of the same register which feature pronominal reference and elliptical structures are contextdependent in the sense that the linguistic means force the hearer/reader to recover the information necessary for full information retrieval from beyond the immediate linguistic context.

In sum, on the one hand, explicitness refers to lexical and grammatical material on the surface of the linguistic structure. Because all sentences, utterances, texts and discourses consist of linguistic material, all of them are explicit - but some feature more explicit information than others. On the other hand, in most of the uses of the term in linguistics explicitness is a measure of difference between two comparable variants of expression. Following this view, for an expression to be considered explicit, there has to be the systemic possibility of an implicit (or less explicit) variant and this dichotomy facilitates distinguishing properties of languages, communicative behaviours and registers. In short, explicitness is a property of the linguistic encoding and it is at the same 
time an inherently relative and relational concept, usually presupposing the comparison of two or more variants.

In translation and interpretation studies the term "explicitness" is used in a slightly different way. While the phenomenon "explicitness" is generally also based on the premise of overt linguistic encoding, it is often considered to be the result of the process or procedure of "explicitation", i.e., "the technique of making explicit in the target text [discourse] information that is implicit in the source text [discourse]" (Klaudy 1998: 80). Explicitness is seen as a feature of translated text as opposed to original text production and is invariably related to the translator/interpreter as the agent in the process of language mediation, who introduces explicitness into the target text/discourse. In translation and interpretation studies, explicitness tends not to be understood as a property that distinguishes preferences for patterns of information structuring, communicative conventions or registers in different languages independent of a translation relation.

The following sections outline the conceptualizations of explicitness and explicitation in translation and interpreting studies in detail.

\subsection{The Notion of Explicitness and Explicitation in Translation and Interpreting Studies}

When considering the concept of explicitness in translation studies, it is useful to distinguish between linguistically-oriented approaches to translation (House 1997, 2006; Steiner 2004; Doherty 2002; Fabricius-Hansen 1996, 1999), which usually employ the term "explicitness" on the one hand, and translation-theory and translation-practice-oriented approaches (e.g. Weissbrod 1992; Olohan and Baker 2000), which tend to consider explicitness in terms of "explicitation" on the other. ${ }^{1}$ Between these two approaches a third, slightly different notion of "explicitation", influenced by discourse analysis, sociology of language, and relevance theory, emerged in interpreting studies. We will summarize these different approaches in turn.

Among the linguistically-oriented approaches at least two could also be categorized as essentially contrastive-linguistic endeavours, employing translations and the shifts in the explicitness of linguistic encoding as indicators of underlying differences between the two language systems involved (Doherty 1995; Fabricius-Hansen 1996, cf. Section 1 above). Others, such as House $(2002,2004)$ and Steiner $(2004,2005$, in press), consider translations from the perspective of an increasing amount of language mediation via translation, which requires, in their view, a systematic description of the text type/register "translation" and its relation to comparable texts in the source language and target language communities. House focuses on translations in terms of 
language contact and source text induced target language variation. She posits a change in the conventions of the explicitness of linguistic encoding in German as a result of translational contact with English (House 2002, 2004). Steiner investigates translations in terms of the properties of translated text as a genuine target language text type (Steiner 2004). Among the linguistically-oriented approaches to translation only Steiner connects explicitness in translations explicitly to explicitation in the process of translation; all others treat explicitness as a measure of difference between the two languages involved in the translation: first, as a property of the linguistic encoding and secondly, as a feature of the higher level unit text resulting from the linguistic encoding on the local level.

In the translation-theory and translation-practice-oriented approaches to explicitness in translation, the focus is placed on explicitation, i.e., the process that results in increased explicitness in the translated text as opposed to its source text. Explicitation is variously described as a "strategy" or "technique" and "process" (Weissbrod 1992; Pápai 2004; Blum-Kulka 1986; Baker 1996; Olohan and Baker 2000). While the first two terms stress the translators' conscious decision to deviate from the information given in the source text, "process" defines explicitation as an involuntary departure from the information given in the source text, evoked by the specific conditions of cognitive language processing during language mediation.

Explicitation seems to have been first defined as a concept by Vinay and Darbelnet (1958). They state that explicitation is the

[p]rocédé qui consiste à introduire dans LA [langue d'arrivée] des précision qui restent dans LD [langue de départ], mais qui se dégagent du contexte ou de la situation (Vinay and Darbelnet 1958/1977: 9).

The concept was further developed by Nida (1964). Without actually using the term explicitation, he distinguishes three main techniques used in the process of translation, namely addition, alteration and subtraction. In his framework explicitation is most easily related to "addition" techniques such as "filling out elliptical expressions", "additions required because of grammatical restructuring", "addition of classifiers and connectives", and additions triggered by "categories of the receptor language which do not exist in the source language" (Nida 1964: 227).

Nida's conception of addition shows that explicitation is basically a twodimensional concept. There is, on the one hand, "obligatory" explicitation caused by grammatical differences between the source and the target language. Without explicitation the target language structures would be ungrammatical. On the other hand, there is "optional" explicitation. ${ }^{2}$ Optional explicitation is due to culture-specific world knowledge in the source and target language 
communities and differences in communicative conventions between these two communities, for example with respect to text building strategies or the overt encoding of the writer persona in the text. In these cases, translation necessitates an adaptation - or "cultural filtering" (House 1997) - to local genres and the intended readers' knowledge base in the target language community.

In the years following Vinay and Darbelnet (1958) and Nida (1964), explicitation in translation has received considerable attention. Most of the investigations into the phenomenon are qualitative in nature and focus on the product perspective, i.e., they chronicle instances of explicitation in translations and suggest explanations for their motivation (e.g. Weissbrod 1992; Øverås 1998; see, however, Olohan and Baker 2000 and Englund-Dimitrova 2005 for qualitative and process-oriented approaches, respectively). In her overview of research on explicitation, Gumul (2006) presents a diverse list of explicitation phenomena, ranging from the lexical to the discourse level of linguistic structure:

- adding connectives

- categorical shifts of cohesive devices (i.e. from lexical reference to proforms)

- shifts from referential cohesion to lexical cohesion

- shifts from reiteration in the form of paraphrase to reiteration in the form of identical/partial repetition

- filling out elliptical constructions

- lexical specification

- addition of modifiers and qualifiers

- addition of proper names to generic names

- distributing the meaning of a source text unit over several units in the target text

- replacing nominalisations with verb phrases

- disambiguating metaphors with similes

- including additional explanatory remarks.

(Adapted from Gumul 2006: 174)

Gumul's paper is a product-and-process study of explicitation in interpreting. The author compares source and target discourse, and links these findings to retrospective comments of the interpreters. She finds that basically most explicitations are not the result of conscious decisions made by the interpreters. In contrast, the majority of explicitations in Gumul's sample remain uncommented by the subjects. Not surprisingly, she concludes that "in most cases explicitation in simultaneous interpreting (SI) appears to be subconscious" (2006: 187). However, as Gumul herself points out, the "incessant time pressure in simultaneous interpreting, coupled with a piecemeal 
picture of the text structure (...) encourage the conclusion that these structures [i.e. shifts from nominalizations to verb phrases] must be used automatically" (ibid.: 184).

Although it is questionable as to which degree retrospective comments of interpreters provide access to cognitive processing during interpreter performance, the mainly non-strategic and subconscious character of explicitation in SI seems to be plausible. However, the pure fact that phenomena such as the adding of connectives or, to a lesser extent, categorical shifts of connectives take place even in the simultaneous mode clearly supports previous studies which point out the specific sensibility of SI for situational and interactional aspects of communication (Monacelli 2006; Setton 2006; cf. also Setton 1999; Vianna 2005; Pöchhacker 1994). In other words, the possible need for linguistic and cultural adaptation is nowadays widely acknowledged. Thus, conscious or not, explicitation can be perceived as a means to overcome the pragmatic underdetermination of what is said and (at the same time) can serve to bridge the gap between local communicative contexts and institutional frames (Mason 2006; Pöchhacker 2004: 134ff).

The notably different understanding of 'explicitation' in interpreting studies and translation studies becomes obvious in Pöchhacker's view that "quite apart from its postulated status as a universal feature of translation, explicitation may be needed as a strategy to circumvent linguistic and sociocultural differences" (Pöchhacker 2004: 135). Thus, in interpreting studies, phenomena like the spelling out of implicatures as described by Mason (2006), or the different types of renditions found by Wadensjö (1998) can be traced back to the specific position of the interpreter as a participant in mediated, triadic interaction.

In translation studies a slightly different view can be found. Because the explicitation phenomena listed above appear so pervasively, and because they occur seemingly irrespective of the languages involved and the translation direction, it has been suggested that explicitation is in fact inherent in the process of translation. The idea was first systematically investigated by BlumKulka (1986) in her study of shifts in cohesion and coherence in translation. She posits what she has called the "explicitation hypothesis" for translation, namely "an observed cohesive explicitness from SL to TL texts regardless of the increase traceable to differences between the two linguistic and textual systems involved" (Blum-Kulka 1986: 19). The explicitation hypothesis has gained much support in translation studies (e.g. Séguinot 1988; Englund-Dimitrova 1993; Øverås 1998; Puurtinen 2004). While Blum-Kulka's explicitation hypothesis refers only to shifts in cohesive markers from the source text to the target text, explicitation is now often considered a translation universal, encompassing linguistic features beyond those responsible for expressing cohesive relations (Vanderauwera 1985; Baker 1992; Schmied and Schäffler 
1997). However, as noted earlier, most of the investigations of explicitation to date are qualitative enquiries into small data sets, which can make only little claim to representativeness or the universality of the observed phenomena (cf. also Tymoczyko 1998).

Returning once more to Blum-Kulka's explicitation hypothesis, we find that she addresses a problem that appears to be rarely addressed in other studies of translational explicitation. Blum-Kulka explicitly acknowledges that there are two types of explicitness: First, different conventions of explicitness between the source and the target language and, secondly, translational explicitness, i.e., the result of explicitation in the process of translation. That means that some shifts in translation cannot be regarded as instances of explicitation because they are caused by differences in the linguistic and textual systems between the two languages. In the sense of Blum-Kulka, only shifts in excess of what is necessitated by the target language system and communicative conventions are genuine instances of explicitation.

The difference between linguistic system and communicative conventions on the one hand and the effects of language mediation on the target language text on the other, brings us back to our initial - linguistic - definitions of explicitness and the question of how to distinguish, in the analysis of translations, between explicitness as a measure of difference between languages and language-specific communicative conventions on the one hand and explicitness in the translated text as a result of conscious or unconscious explicitation processes by the translator on the other. For example, contrastive analyses of translations from English into German and comparable German original text production in several German written genres show that both translations and German original texts are characterized by a preference for referential explicitness and for presenting the subject matter in a semantically precise, strongly cohesive and informationally dense manner (Böttger and Probst 2000; House 2004). That is, both German translations and German original texts are more explicit than comparable English texts. Therefore, an investigation limited to the source text and its translation can hardly reveal anything about which additional linguistic phenomena have to be ascribed to the translation process as such and which are triggered by prevalent communicative preferences and textual norms in German. As a consequence, it is virtually impossible to assess the role of the translator in the translation process.

Therefore, in order to tease apart the translation process and crosslinguistic differences in the explicitness of linguistic encoding, the analysis of explicitation in translation must involve, first, a clear conception of the relation between explicitness as a language-specific property of linguistic encoding and explicitation as a process or procedure of language mediation and, secondly, a contrastive analysis of translations and comparable original texts in the target language. Furthermore, detailed micro-analyses of explicitations and their 
linguistic context are needed in order to avoid premature generalizations on the nature and background of these phenomena. In Section 3, we will present two exploratory investigations to support our view that explicitness and explicitation do not result from oral or written translation per se, but are rather triggered by stylistic preferences of the target language and/or by specific participant constellations within the triad.

\section{SHIFTS OF EXPLICITNESS IN WRITTEN TRANSLATION AND SIMULTANEOUS INTERPRETING}

\subsection{Explicitness, Explicitation and Parentheticals in Translations}

Before we set out to describe the use of parentheticals as markers of explicitness and the site of writer/translator based explicitation, we will first, briefly, illustrate the amount of additional linguistic elements found in a German translation of an English text. Consider example (1), an excerpt from a popular science magazine article.

Example (1)

\begin{tabular}{|c|c|}
\hline English source text & German translation \\
\hline $\begin{array}{l}\text { In an eternal universe, potentially of } \\
\text { infinite volume, one might hope that } \\
\text { a sufficiently advanced civilization } \\
\text { could collect an infinite amount of } \\
\text { matter energy and information. } \\
\text { Surprisingly, this is not true. Even } \\
\text { after an eternity of hard and well- } \\
\text { planned labor living beings could } \\
\text { accumulate only a finite number of } \\
\text { particles, a finite quantity of energy } \\
\text { and a finite number of bits of } \\
\text { information. What makes this failure } \\
\text { all the more frustrating is that the } \\
\text { number of available particles, ergs } \\
\text { and bits may grow without bound. } \\
\text { The problem is not necessarily the } \\
\text { lack of resources but rather the } \\
\text { difficulty in collecting them. }\end{array}$ & $\begin{array}{l}\text { In einem unendlichen Universum mit } \\
\text { einem unendlichen Volumen könnte } \\
\text { ja die Hoffnung aufkommen, daß ei- } \\
\text { ne hinreichend entwickelte Zivilisa- } \\
\text { tion auch unendliche Mengen an } \\
\text { Materie, Energie und Information } \\
\text { anzusammeln vermag. } \\
\text { Überraschenderweise ist das jedoch } \\
\text { nicht möglich. Auch nach einer be- } \\
\text { liebig langen Zeit harter Arbeit kön- } \\
\text { nen, so unsere These, Lebewesen } \\
\text { nur eine begrenzte Menge an Mate- } \\
\text { rie, Energie und Information (Bits) } \\
\text { zusammentragen. Was das Ganze } \\
\text { noch frustrierender macht, ist die } \\
\text { Tatsache, daß die Zahl aller insge- } \\
\text { samt im Kosmos vorhandenen Mate- } \\
\text { rieteilchen, Energie- und Informati- } \\
\text { onseinheiten anscheinend dennoch } \\
\text { über alle Grenzen anwachsen kann. } \\
\text { Das Problem ist daher nicht unbe- }\end{array}$ \\
\hline
\end{tabular}




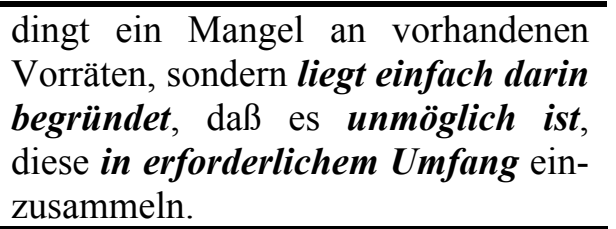

Excerpt from a popular science magazine article: Lawrence M. Krauss, Glenn D. Starkman: "The Fate of Life in the Universe" Scientific American, November 1999: 36-43 and Lawrence M. Krauss, Glenn D. Starkman: "Das Schicksal des Lebens im Universum", Spektrum der Wissenschaft, January 2000: 52-59 (additional linguistic elements in bold italics).

The German translation is noticeably longer than its English source text, as it contains numerous additional elements. With respect to the amount of information overtly encoded in linguistic material, the German translation is more explicit than its source text. The explicitations in this excerpt are all optional, i.e., they are not caused by grammatical differences between the source and the target language. Looking at the various explicitations in more detail, we can classify them as additional information (e.g. "insgesamt im Kosmos"), connectives (e.g. "auch"), the writer's evaluation of the proposition (e.g. "ja"), more specific information (e.g. "in erforderlichem Umfang") and the addition of specialized terminology ("Bits"). All but one of the additions are covertly placed into the translated text. In the case of "(Bits)", however, rounded brackets are used to insert the specialized terminology, which clearly marks it as having a different information status than the rest of the sentence. In the following analysis, we will focus on bracketing as one possible type of marking explicitation.

Together with other orthographic elements such as dashes and colons, brackets are used to delimit "parentheticals". Biber et al. (1999) define a parenthetical structure as "a digressive structure [...] which is inserted in the middle of another structure, and which is unintegrated in the sense that it could be omitted without affecting the rest of that structure or its meaning" (Biber et al. 1999: 1067). With respect to their function, they say that "[p]arenthetical elements are used [...] to give additional information which is related to, but not part of, the main message of the clause" (Biber et al. 1999: 137). As the notion of providing additional information is also taken up in other definitions of parentheticals (Behrens 1989; Zifonun et al. 1997; Nerius 2000), one can say that this seems to be their main function.

The use of brackets as markers of parentheticals presents a sharp interruption in the information organization of a sentence (Quirk et al. 1985). In German, the use of brackets as graphological signs for parentheticals is 
regarded as stylistically marked in many types of written texts. Most style guides to writing in German do not even mention the use of brackets as an option of marking parentheticals, the unmarked alternatives being colons and dashes, due to the fact that brackets are predominantly associated with the group of mathematical operators. As such, their unmarked occurrence as markers of parentheticals is very much restricted to technical and specialized scientific writing. In contrast, in English writing, the use of brackets as markers of parentheticals appears to be more common (e.g. Fairbairn and Winch 1996).

The above mentioned definitions of parentheticals show that it is necessary to consider them both with respect to their function in connection with the proposition of the carrier structure and their syntactic relation to the carrier structure. In this regard, Dale (1992) posits that "punctuation may mark the degree of semantic "importance" of various constituents, e.g. parentheticals are less important syntactically and semantically to the sentence as a whole" (cf. Dale 1992, see Doran 1998).

Syntactically, the omission of a parenthetical causes no problems; as parentheticals are said to be independent, they can be omitted with the embedding sentence still being grammatical (Hoffmann 1998; Bußmann 1990). According to Hoffmann's (1998) functional syntactic approach, this can be explained by the fact that parentheticals do not occupy a position in the embedding sentence that is essential with regard to valency. Rather, parentheticals occupy a place within the linear structure of the sentence but outside its syntactic bindings (Hoffmann 1998: 300ff). Hoffmann emphasizes that the above mentioned independency of the embedding structure is probably only valid for the syntax of the sentence and criticizes that parentheticals are sometimes treated as Nebeninformationen ('secondary information') (see also Schneider 2007). According to him, without the parenthetical, the meaning of the whole sentence would not be the same (Hoffmann 1998: 304ff). ${ }^{3}$ Finally, Hoffmann characterizes parentheticals as insertions in the linear structure which are functionally not integrated and have to be processed on a parallel level (Hoffmann 1998: 307).

In sum, in written texts parentheticals are graphologically marked, for example by colons, dashes or brackets. Parentheticals contribute to the level of explicitness in a text in that their special information status with regard to the carrier structure is overtly encoded by orthographic means. Brackets elevate the information inside, i.e., the parenthetical, to a special information status with respect to the information of the carrier structure. The parenthetical has a qualitatively different information status from the rest of the sentence. Brackets, as it were, add the information < different from the carrier structure> to the information encoded inside the brackets. The graphological marking of parentheticals indicates to the reader that the information inside is not directly related but nevertheless relevant to the topic under discussion. Bracketing can 
also be seen as a method of stressing the presence of a writer in the text who is involved in information organization, as brackets signal that different pieces of information in the sentence are given different information statuses.

\subsubsection{Parentheticals in translations and original text production}

The analysis was carried out on the basis of an English-German translation and comparable text corpus of popular scientific writing (Figure 1). Translation and comparable text corpora are useful tools for conducting fine-grained analyses of both the systematic and stylistic similarities and differences between languages on the basis of authentic data and actual usage (see, e.g., Aijmer and SimonVandenbergen 2006). They can provide insight into whether equivalent linguistic items are found in the same linguistic contexts in both languages, whether equivalent linguistic items are used for the same communicative purpose and whether the source text and translation text structures fulfill the same communicative function in their contexts of occurrence. Figure 1 shows the translation and comparable text corpus used in this study.

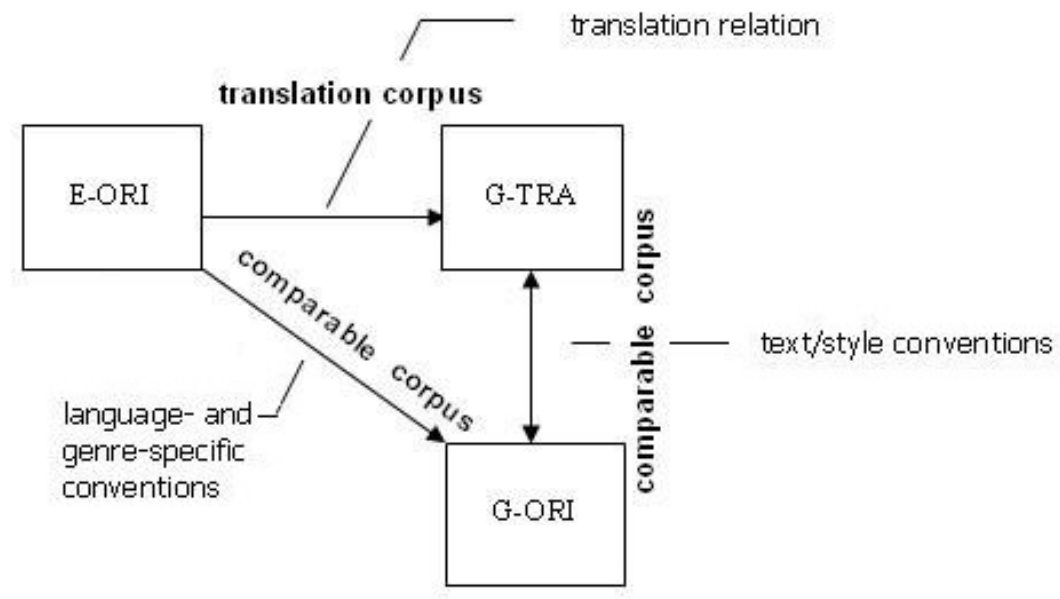

Figure 1. Translation and comparable text corpus

The translation part of the corpus contains English texts (E-ORI) and their translations into German (G-TRA). This part of the corpus facilitates the investigation of the particular features of the translation relation EnglishGerman. The comparable part of the corpus contains 
(a) English texts (E-ORI) and non-translated German texts (G-ORI). They are analyzed with respect to the linguistic realization of language and genre specific conventions of text production;

(b) German translations from English (G-TRA) and non-translated German texts (G-ORI). They are analyzed with respect to the (potentially different) characteristics in the use and combination of lexicogrammatical features in original texts and translations in German.

The corpus consists of the following sets of texts from the years 1999-2002. The texts were sampled from the English journals Scientific American and New Scientist and from the German journal Spektrum der Wissenschaft.

1. English original texts from the years 1999-2002 (122,866 words).

2. The German translations of the English original texts (113,420 words).

3. German original texts from the years 1999-2002 (100,648 words).

For the present investigation, all occurrences of parentheticals marked by rounded and square brackets in combination with an extended context of occurrence were extracted from the corpus. Then every parenthetical was analyzed for its meaning and communicative purpose with respect to the carrier structure.

In the following analysis of explicitness in translations and explicitation we focus on the use of parentheticals of the type introduced in example (1) above. Another example is presented in (2).

Example (2)

$[T]$ hey kept records on bone and stone plaques; they made music on wind instruments; they crafted elaborate personal adornments; they afforded some of their dead elaborate burials with grave goods (hinting at social stratification in addition to belief in an afterlife, for not all burials were equally fancy); their living sites were highly organized, with evidence of sophisticated hunting and fishing.

In English popular scientific writing of the type investigated here, parentheticals in brackets are used to express a number of specific meanings in relation to their carrier structure: ${ }^{4}$

1. to give abbreviations for the immediately preceding term

2. to give the full expression for an acronym, blendings or other types of word formation 
3. to give an example for the phenomenon denoted by the proposition outside the parenthesis

4. to elaborate the proposition

5. to give an explicitly writer-based elaboration of the proposition

6. to reformulate information

7. to give an explanation of the phenomenon denoted by the proposition in non-specialist, everyday language

8. to refer the reader to pictorial material in the text or to other articles on the same topic.

In German popular scientific writing, both translated and non-translated, parentheticals in brackets fulfill the same functions. However, they also express a number of additional meanings which are not found in English texts: ${ }^{5}$

1. to give bibliographical references

2. to give translations or foreign-language terms for specialized vocabulary

3. to give geographical locations

4. to give biographical data of persons and historical dates.

In translations, parentheticals can be used as a means of explicitation. In a sense, brackets could be regarded as typical sites of translational explicitation. Much in the same way as in original text production, parentheticals can contain explanations of previous expressions, can elaborate previous information by providing additional information that the translator deems necessary for the understanding of the sentence, or that he/she finds useful for the understanding of the subject matter of the text as a whole. Because parentheticals explicitly mark off the information that is added from the rest of the text and sentence structure, they allow the translator to incorporate information without deviating too much from the source text. At the same time, the translator becomes discernible as the agent of language mediation in the text.

In our corpus of translated and non-translated popular scientific writing in English and German, we find parentheticals in both translations and original text production. Hence, the question arises as to whether the parentheticals in translations are the product of translational explicitation or instances of cultural filtering, i.e., adaptations to the textual/discoursal explicitations conventional in the target language.

\subsubsection{Translational explicitation vs. 'cultural filtering'}

In the interpretation of the data, we follow Blum-Kulka's (1986) conceptualization of explicitation that only shifts in excess of what is necessitated by 
the target language system and communicative conventions are genuine instances of translational explicitation. Shifts that can be related to differences between the source and the target language system and communicative conventions are considered as instances of cultural filtering (House 1997), i.e., adaptations to the target language system and communicative conventions. In other words, translational explicitation requires that German translations show more instances of a single type of parenthetical than both their English source texts and comparable German texts. If German translations show more instances of a single type of parenthetical than their English source texts but equal to or less than German non-translated texts, the instances in the German translations have to be considered as (incomplete) cultural filtering, i.e., the result of adaptation to target-language textual norms. In Table 1 we present the overall frequencies of brackets in English non-translated texts (E), German translations (GT) and German non-translated (G) texts.

Table 1

Frequencies for parentheticals (raw frequencies and percentages of the total of sentences in the data set)

\begin{tabular}{|c|c|c|c|c|c|}
\hline E & $\%$ & GT & $\%$ & G & $\%$ \\
\hline 449 & 7.78 & 456 & 7.18 & 607 & 11.01 \\
\hline
\end{tabular}

E: $N=5771$ sentences; GT: $N=6344$ sentences; $G: N=5511$ sentences

The German translations show fewer occurrences of parentheticals in rounded and square brackets than both non-translated English and German texts. At first sight, this result seems to indicate that translators are more conservative in the use of parentheticals than writers of German original texts. They seem to merely reproduce the parentheticals found in the source texts without inserting any additional ones. In this sense, parentheticals do not seem to be a strategy of explicitation applied by the translator, and the translations would even have to be considered a little less explicit because they actually feature less overt markers - i.e. brackets - of information structuring on sentence and textual level in the texts compared to their source texts. Another explanation for the results could be that translators avoid using brackets as markers of parentheticals so that information which could be (and is in German nontranslated texts) lexicalized in a bracketed parenthetical, is otherwise, covertly, integrated into the syntactic or textual structure of the translation.

The analysis of the translation relation between the parentheticals in the German translations and their English source texts, however, revealed that 307 of the total 456 occurrences of parentheticals in the German translations have 
no structural equivalent in the English source texts. Altogether $284(92.5 \%)$ of these are additions containing information neither explicitly nor implicitly encoded in the source texts. In what follows we will focus on these 284 parentheticals in the German translations which are neither structurally nor semantic-pragmatically motivated by their source texts. Table 2 shows the distribution of parentheticals in the three data sets across the different types of parentheticals found in the corpus.

Table 2

Distribution of parenthetical types

\begin{tabular}{lrrrrrr}
\hline & $\begin{array}{c}\mathrm{E} \\
(\mathrm{N}=449)\end{array}$ & \multicolumn{1}{c}{$\%$} & $\begin{array}{c}\mathrm{GT} \\
(\mathrm{N}=284)\end{array}$ & $\%$ & $\begin{array}{c}\mathrm{G} \\
(\mathrm{N}=607)\end{array}$ & \multicolumn{1}{c}{$\%$} \\
\hline Full expression for acronym & 3 & 0.7 & 5 & 1.8 & 26 & 4.3 \\
Abbreviation & 39 & 8.7 & 8 & 2.8 & 27 & 4.4 \\
Example & 15 & 3.3 & 0 & 0 & 6 & 1.0 \\
Elaboration & 122 & 27.2 & 31 & 10.9 & 88 & 14.5 \\
Writer-based elaboration & 67 & 14.9 & 18 & 6.3 & 40 & 6.6 \\
Explanation in everyday terms & 44 & 9.8 & 25 & 8.8 & 32 & 5.3 \\
Specialized terminology & 28 & 6.2 & 36 & 12.7 & 98 & 16.1 \\
Reformulation & 12 & 2.7 & 3 & 1.0 & 15 & 2.5 \\
Reference & 0 & 0 & 0 & 0 & 11 & 1.8 \\
Reader-oriented exophoric and & 119 & 26.5 & 107 & 37.7 & 196 & 32.3 \\
intertextual reference & & & & & & \\
Translation of foreign-language & 0 & 0 & 5 & 1.8 & 2 & 0.3 \\
terminology & 0 & 0 & 36 & 12.7 & 32 & 5.3 \\
Geographical information & 0 & 0 & 10 & 3.5 & 34 & 5.6 \\
Biographical, historical data & & & & &
\end{tabular}

In the English texts, the majority of parentheticals are (explicitly writer-based) "elaborations" and "reader-oriented, exophoric and intertextual reference" to graphics in the texts and related articles in previous issues of the magazines. In these texts, parentheticals predominantly serve functions related to the communicative event between the writer and the reader in that the readers' knowledge base and interests are anticipated, their attention is guided to additional information outside the texts, and the writers inscribe themselves as personally involved in the communication with the readers. In the German texts, the largest number of parentheticals contains "reader-oriented exophoric and intertextual reference". The two next most frequent types are "introduction of specialized terminology" and "(writer-based) elaboration". Evidently, English and German popular scientific writing are governed by different conventions of lexicalizing/encoding (writer-based) elaborations of the proposition. The German translations, finally, explicate, i.e., introduce into the translations, most 
frequently "reader-oriented exophoric reference and intertextual information", "specialized vocabulary" and "geographical information". "Reader-oriented exophoric and intertextual reference", however, can hardly be counted as explicitation on the part of the translator, since this type of reference could just as well have been added to the translation by the editors.

Following our definition of translational explicitation, we only find indications of translational explicitation with respect to reader-oriented exophoric and intertextual reference, the translation of foreign-language terminology and geographical information. We may rule out reader-oriented exophoric and intertextual reference as editorial rather than translational explicitation. In addition, explicitation of geographical information could be likewise inconclusive because the sample of German translations may feature more references to geographical locations than the sample of German texts. That would leave the addition of translations of foreign-language terminology as the only instances of translational explicitation in our corpus.

Of course, one could argue that parentheticals in brackets are just no good candidates for the investigation of explicitation because they are a structural (or even only a superficial orthographic), rather than a linguistic phenomenon with specific communicative functions, which need to be preserved in translation and which therefore may also be added in the process of translation. On the other hand, however, there is some evidence that parentheticals are affected by translation. Some types of parentheticals are used with similar frequency in translations and non-translated German texts, which suggests that there are conventions in German for using brackets of which the translators are aware. The type "(writer-based) elaboration", for example, shows 'cultural filtering' in the sense that this type of explicitation occurs with comparable frequency in the German translations and the non-translated German texts. The same is true for the types "full expression for acronym", "reformulation" and "introduction of specialized vocabulary". "Explanations in everyday terms", in contrast, are almost as frequent in translations as in the English texts, which could be seen as an indication that this function of parentheticals overrides conventionalized constraints on the use of parentheticals in German popular scientific writing.

In sum, although more than $60 \%$ of the parentheticals in the German translations are not licensed by their source texts, only a very small fraction can be considered as the result of translational explicitation. The vast majority of parentheticals, however - which undoubtedly raise the explicitness of the translations in comparison to their English source texts - are used to align the translations with the conventions of use for parentheticals in the German targetlanguage genre. The latter type of explicitation may or may not be beyond the conscious control of the translator (and as such inherent in the process of translation), but it is, seemingly, not specific of German translations but rather 
of German text production in the genre of popular scientific writing as it is represented in our corpus.

\subsection{Explicitations and Place Names: How Two Simultaneous Interpreters Render the Word Amazônia 'Amazon Region'}

In this section, we will analyse the hypothesis of explicitation as a translation universal in relation to interpreter-mediated discourse. The hypothesis implies that explicitation is related, in one way or the other, to the translation task as such, independently of individual differences between translators or intense cultural and linguistic contrasts. As a consequence, one should expect to find explicitation even in cases in which cultural or linguistic adaptations are not obligatory.

While explicitations of cohesive devices may also be related to shifts on the oral-literate continuum (Bührig and Rehbein 2000; Pöchhacker 2004), the use of proper names provides an opportunity for studying explicitation in a context that is less influenced by stylistic norms. In general, it is assumed that proper names do not need to be translated and that slight phonological adaptations are usually sufficient in order to integrate proper names into the target text or discourse (Kelletat 1998). However, we will suggest that the use of proper names in interpreted discourse is not always that trivial. Referring to knowledge about places or persons by using their names presupposes a similar level of knowledge on the side of the listener which the interpreter or the listener, or even both, may not necessarily be equipped with.

Furthermore, names may be redundant if other, generic characterizations of the respective person or place are available in the source text. Therefore, in contrast to what is generally assumed, references to persons or places may be constructed differently in the target discourse, although such divergent renditions are not necessarily the result of linguistic or cultural differences. However, one should expect that names are simply repeated by interpreters in those cases when neither cultural or knowledge-related differences, nor problems relating to processing or memory exist.

In the following section, we explore the use of the place name Amazônia by two interpreters. The data come from a public talk by a Brazilian speaker to a German audience. In this talk, a Brazilian rainforest activist speaks about the plantation of genetically modified soy in Brazil and the related social and environmental consequences for the Amazon basin. The talk was held in front of an audience consisting of German environmental activists and students from the Institute for Interpreting and Translation Studies at the University of Heidelberg. There were four professional interpreters in two teams providing professional simultaneous interpreting (SI) for the rather mixed audience, using 
the conference equipment of the institute. The simultaneous performance of the two experienced and professional SI-teams resulted in a small corpus of comparable SI-performance under natural conditions. Furthermore, a few days before the Heidelberg event, the same Brazilian speaker spoke about the same topic in two other German cities (Berlin and Hamburg) in front of a similar audience. At these two occasions, the interpreting mode was consecutive and the interpreters were once again professionals, one of them was also involved in the simultaneous interpretation at Heidelberg.

Example (3)

\begin{tabular}{|c|c|c|}
\hline $\begin{array}{c}\text { Brazilian speaker } \\
((39 \mathrm{~m}: 51 \mathrm{~s}))\end{array}$ & $\begin{array}{l}\text { Interpreter no. } 2 \\
((40 \mathrm{~m}: 02 \mathrm{~s}))\end{array}$ & $\begin{array}{c}\text { Interpreter no.5 } \\
((39 \mathrm{~m}: 54 \mathrm{~s}))\end{array}$ \\
\hline $\begin{array}{l}((1 \mathrm{~s})) \text { Essa soja } \bullet \bullet \text { que } \\
\text { tá sendo plantada na } \\
\text { Amazônia } \bullet \bullet \text { vem toda } \\
\text { de terras griladas, ou } \\
\text { boa parte. }\end{array}$ & $\begin{array}{l}\text { Die Sojaproduktion in } \\
\text { Pará und auch im } \\
\text { Amazonasgebiet } \\
\text { geschieht nun } \\
\text { hauptsächlich auf } \\
\text { widerrechtlich } \\
\text { angeeignetem } \\
\text { Bundesland. }\end{array}$ & $\begin{array}{l}\text { Und } \bullet \cdot \text { die Soja, } \bullet \text { die in } \\
\text { Amazonien angebaut } \\
\text { wird, } \bullet \cdot \text { kommt aus } \\
\text { Gebieten, } \bullet \cdot \text { die man } \\
\text { sich eigentlich } \\
\text { widerrechtlich } \\
\text { angeeignet hat. }\end{array}$ \\
\hline $\begin{array}{l}\text { This soy that is } \\
\text { currently planted in } \\
\text { Amazonia comes } \\
\text { entirely from illegally } \\
\text { acquired federal } \\
\text { estates, or at least most } \\
\text { of it. }\end{array}$ & $\begin{array}{l}\text { The soy production in } \\
\text { Para and also in the } \\
\text { Amazon region takes } \\
\text { place mainly on } \\
\text { illegally acquired } \\
\text { federal estates. }\end{array}$ & $\begin{array}{l}\text { And the soy that is } \\
\text { planted in Amazonia } \\
\text { comes from areas that } \\
\text { were actually acquired } \\
\text { illegally. }\end{array}$ \\
\hline
\end{tabular}

Translation of Amazônia into German by two simultaneous interpreters. Transcription conventions: - mark short hesitations of less than a second, - mark pauses of a second, underlining marks emphasis on the underlined syllable.

In example (3), an excerpt from the Heidelberg conference is presented in order to show a part of the discursive context in which the word Amazonia is being used. At this point the Brazilian speaker is speaking about issues of landownership and then establishes a link to soy production. Interpreter 2, who renders Amazônia by using the more explicit German term, has a time lag of eleven seconds, while Interpreter 5 lags only three seconds behind the Brazilian 
speaker. These differences in the time lag correspond to the different linguistic features of the renditions. While Interpreter (2) deviates from the original in structural terms by creating an assertion without embeddings, interpreter (5) reproduces the original main clause relative clause construction. Both interpreters, however, leave out propositional parts like the appended restriction ou boa parte 'or at least most of it' or the quantifier toda 'entirely'. Furthermore, both manage to render the technical term terra grilada 'illegally acquired federal estate'. Nevertheless, the version of interpreter (2) is more explicit: he mentions that the implication terra grilada refers to federal estates, whereas Interpreter (5) uses the more general expression Gebiet 'area'. Another difference between the two renditions is that Interpreter (2) renders the place name Amazônia with Amazonasgebiet 'Amazon region', whereas Interpreter (5) uses the word Amazonien.

The rendition of Amazônia from Brazilian Portuguese into German, as presented in example (3), is at first glance not a very interesting object of study. In a meeting on rainforest issues there is no need to explain the meaning of this place name, and even the phonological adaptation to German refers mainly to the derivational affix "-ia" which in German is "-ien" (Amazonien). The German affix "-ien" is used to create names both for geographical areas such as Sibirien 'Siberia', or for names of countries such as Tunesien 'Tunisia'. However, the second option for translating Amazônia into German, which is Amazonasgebiet 'Amazon region', is equally acceptable and probably even slightly more frequent than Amazonien.

The difference between the two words is that, looked at from a structural and semantic point of view, Amazonasgebiet is more explicit than Amazonien. This makes the word an interesting object of study with regard to the hypothesis of explicitation as a translation universal. While Amazonien is composed of the nominal stem Amazon- and the derivational affix, Amazonasgebiet is a compound consisting of two nouns that can be processed independently. The nominal head -gebiet (area) prevents any misunderstanding, especially with respect to any possible confusion between the Amazon region as a geographic entity encompassing parts of Brazil, Peru, Venezuela, etc., and those parts of the Amazon region which are part of the Brazilian federal states of Amazonas, Acre, Roraíma, etc., and have a special legal status (Amazônia legal). Thus, while Amazonien could be used in order to refer to either of these slightly different meanings, Amazonasgebiet refers exclusively to the Amazon region as a geographic entity - with the generic meaning of the nominal head dominating the compound as a whole. Therefore, the word Amazonasgebiet is less ambiguous and more explicit than Amazonien.

If the hypothesis of explicitation as a translation universal is correct, German interpreters should therefore prefer the term Amazonasgebiet ahead of 
Amazonien when rendering the place name Amazônia into German. As Table 3 shows, this is however only partly true.

Table 3

Renditions of Amazônia into German in consecutive and simultaneous interpreting

\begin{tabular}{|l|c|c|c|c|c|}
\hline Event/Interpreter & Amazonien & Amazonasgebiet & $\begin{array}{c}\text { Other } \\
\text { nouns }\end{array}$ & Pronouns & $\begin{array}{c}\text { Lack of } \\
\text { rendition }\end{array}$ \\
\hline Berlin / (1) & 3 & 5 & - & - & - \\
\hline Hamburg / (2)* & 3 & 7 & 4 & 2 & 1 \\
\hline Heidelberg / (3) & - & 1 & - & - & - \\
\hline Heidelberg / (2)* & 4 & 9 & - & - & 3 \\
\hline Heidelberg / (4) & - & 1 & - & - & - \\
\hline Heidelberg / (5) & 15 & - & - & - & 1 \\
\hline
\end{tabular}

*Interpreter (2) participates in both Hamburg and Heidelberg.

In Table 3, we counted only those instances in which the Brazilian speaker specifically uses the noun Amazônia referring to the Amazon region in the more general, geographical sense, not to the legal entity. Variants such as Amazônia brasileira 'Brazilian Amazon region' or adjectives as in povos amazonicos 'Amazonian people' were excluded from the survey.

The results presented in Table 3 show that in sum, the terms Amazonasgebiet and Amazonien are used with almost the same frequency. However, the figures differed considerably among the subjects. The main difference can be found in the simultaneous mode applied in Heidelberg: while the interpreters (3) and (4), who interpreted simultaneously during the first half of the talk, had only one rendition of Amazônia, the interpreters (2) and (5) had to render the place name sixteen times. While interpreter (2) switches between nominal and pronominal options, and sometimes even fails to render the word, interpreter (5) almost exclusively renders Amazônia with Amazonien.

This evidence somehow disagrees with the expectation that explicitations should occur even when there is no need for them. There is nothing that hinders interpreter (5) in using the more explicit expression Amazonasgebiet instead of Amazonien. Nevertheless, he sticks to the less explicit and potentially ambiguous term which he chose at the beginning. At this point, it is important to highlight that all interpreters in this sample had the opportunity to prepare themselves for the talk, as they were handed a manuscript beforehand, and they are all experienced conference interpreters. Thus, differences with respect to their professional status or experience can be ruled out as a reason for this contrast. 
Instead of supporting claims for translation universals, the differences found between interpreter (2) and interpreter (5) rather support the suggestion that explicitation is a gradual phenomenon, which depends on three different types of variables: (a) the interpreting mode, (b) individual differences between interpreters such as time-lag, chunking, or experience, and (c) constellation features such as social distance, professional status, and linguistic and cultural differences between speaker and audience. All these variables can, in our view, influence the occurrence of explicitation in different interpreter-mediated settings. Thus, we claim that explicitation is not a universal feature of interpreting, but rather an option that may be more frequent in certain settings or interpreting modes without, however, being restricted solely to these constellations. Thus, we would expect explicitations to be triggered by a certain lack of convergence between speaker and audience with respect to their social status and expertise, language type, or cultural background. Furthermore, experienced interpreters in the simultaneous mode should be less tempted to add to the speaker's contributions, but even they can do so if the other facets come into play.

\section{CONCLUSION: AGAINST A UNIFIED CONCEPT OF EXPLICITNESS}

In the present paper, we tried to grasp the elusive concept of explicitness in translation and interpreting using our own data sets. For this, it was first of all necessary to define the notion of explicitness in linguistics and in translation and interpreting studies (Section 2). In Section 3, we looked at parentheticals as markers of explicitness in translations, focusing on parentheticals marked with brackets. In this context we described parentheticals from a formal and a functional perspective, followed by an overview of the use of parentheticals in translations and original texts. We then illustrated the database and methodology for the English-German translation and comparable text corpus of popular scientific writing before presenting an analysis of the data with regard to translational explicitation and cultural filtering. Finally, we looked at explicitation in interpreting, focusing on place names and the different ways in which interpreters render the same word.

The two small-scale investigations of explicitness and explicitation in translations and interpreting presented in this paper have shown that explicitation in language mediation is clearly not a universal phenomenon. Sometimes it occurs, sometimes it does not, and when it occurs it is - in translation at least - more often than not an explicitation triggered by the communicative conventions and stylistic norms of the target language community rather than being inherent (i.e. beyond the control of the translator) 
in the process of translation. When source and target language speech communities differ with respect to the amount of meaning conventionally explicitly encoded in linguistic material, there will be many instances of explicitation in translations, but the majority of these will be necessary in order to elevate the translation to the level of linguistic explicitness expected in the target language community. In order to establish explicitation as a truly translational phenomenon it does not suffice to compare source and translation text. Rather, corpus-based investigations have to include comparable texts in the target language which serve as a base-line for the linguistic make-up expected in the target language genre. It is only in such a triangular set-up of source text, translation text and comparable text(s) in the target language that the phenomenon of translational explicitation can be reliably identified. The description of these 'real' instances of translational explicitation can offer insights into the (cognitive) process of translation and into translation as a text type of its own.

For the study of interpreter-mediated discourse, our analysis highlights the importance of constellation features, but also individual differences between interpreters and their styles of interpreting. While textual genres are much more sensitive to detailed linguistic norms, spoken discourse tolerates and even requires individuals with a sense for the specific speech situation, the constellation between speaker(s) and listener(s), and the immediacy of verbal interaction. Thus, it appears as if translation in general is in fact dependent on a variety of factors, such as linguistic norms, stylistic conventions, situational features and individual preferences, and that it cannot be readily characterized in terms of universal properties which occur without exception in all kinds and all instances of language mediation.

\section{Notes}

\footnotetext{
${ }^{1}$ See also Heltai (2005) for an account of explicitness from the perspective of processing ease.

${ }^{2}$ See e.g. Klaudy (1993) and House (2005) for taxonomies of explicitation/explicitness.

${ }^{3}$ For contrary views on the information status of parentheticals, see e.g. Meyer (1987) and Gallmann (1985), and for a critical view of Hoffmann (1998), see v. Kügelgen (2003).

${ }^{4}$ Examples for parentheticals in English and German texts:

1. To give abbreviations for the immediately preceding term: Verification of this connection came with another technological revolution: the chargecoupled device $(C C D)$, the light-sensitive chip found in camcorders and digital cameras.

2. To give the full expression for an acronym, blendings or other type of word formation: Devices that rely on an electron's spin to perform their functions form the foundation of spintronics (short for spin-based electronics), also known as magnetoelectronics.
} 
3. To give an example for the phenomenon denoted by the proposition outside the parenthesis:

Before the age of six, most children speak out loud to themselves frequently, reminding themselves how to perform a particular task or trying to cope with a problem, for example. ("Where did I put that book? Oh, I left it under the desk.")

4. To elaborate the proposition:

All these are memes (or conglomerations of memes), because they are copied from person to person and vie for survival in the limited space of human memories and culture.

5. To give an explicitly writer-based elaboration of the proposition:

Subsequent work by Mundt, Bo Reipurth of the European Southern Observatory in Santiago, Chile, and others (including me) showed that jets from young stars stretch for several light-years.

6. To reformulate information:

To achieve a goal in work or play, for instance, people need to be able to remember their aim (use hindsight), prompt themselves about what they need to do to reach that goal (use forethought), keep their emotions reined in and motivate themselves.

7. To give an explanation of the phenomenon denoted by the proposition in non-specialist, everyday language:

Second, whereas the baryons and CDM were initially well mixed, the baryons today form dense knots (the galaxies) inside gargantuan halos of dark matter.

8. To refer the reader to pictorial material in the text or to other articles on the same topic: ADHD involves two sets of symptoms: inattention and a combination of hyperactive and impulsive behaviors [see table on next page].

${ }^{5}$ Examples for parentheticals occurring exclusively in German original texts and German translations:

1. For bibliographical references:

"Ueberhaupt aber [könnte] ein solcher Käfig, in dem die Götter der Erde sich verkriechen müssen, wenn der Gott des Himmels zu donnern anfängt, Raum zu allerley Witz geben" (an Hollenberg, 18.2.1788).

2. For translations or foreign-language terms for specialized vocabulary:

Auch konnten die Daten der Voyager-Raumsonden keine Erklärung für eine sehr filigrane äußere Fortsetzung der Ringe liefern, den so genannten Gossamer-Ring. (Das englische Wort gossamer bedeutet "feine Gaze".)

3. For geographical locations:

Mit dem Strömungsfeld im flüssigen Erdkern hat ein von Glyn Roberts an der Universität Newcastle upon Tyne (England) vorgeschlagenes Geschwindigkeitsfeld eine gewisse Ähnlichkeit:

4. For biographical data of persons and historical dates:

In Texten wird sie mehrfach erwähnt, und ein Relief im Grab des Arztes Anchmahor in der Nekropole von Sakkara aus der Zeit der 6. Dynastie (229-2157 vor Christus) zeigt das Vorgehen sehr detailliert.

\section{References}

Aijmer, K. \& Simon-Vandenbergen, A. (eds.) 2006. Pragmatic Markers in Contrast. Amsterdam, Philadelphia: Benjamins.

Baker, M. 1992. In Other Words. A Coursebook on Translation. London: Routledge.

Baker, M. 1996. Corpus-Based Translation Studies. The Challenges that Lie ahead. In: Somers, H. (ed.) Terminology, LSP and Translation: Studies in Language Engineering in Honour of Juan C. Sager. Amsterdam, Philadelphia: John Benjamins. 233-250. 
Behrens, B. 2004. Cohesive Ties in Translation: A Contrastive Study of the Norwegian Connective Dermed. Languages in Contrast Vol. 5. No.1. 3-32.

Behrens, U. 1989. Wenn nicht alle Zeichen trügen. Interpunktion als Markierung syntaktischer Konstruktionen. Frankfurt M., Bern, New York, Paris: Lang.

Biber, D., Johansson, S., Leech, G., Conrad, S., Finegan, E. 1999. Longman Grammar of Spoken and Written English. London: Longman.

Biber, D. 1988. Variation across Speech and Writing. Cambridge: Cambridge University Press.

Blum-Kulka, S. 1986. Shifts of Cohesion and Coherence in Translation. In: House, J. \& BlumKulka, S. (eds.) Interlingual and Intercultural Communication: Discourse and Cognition in Translation and Second Language Acquisition Studies. Tübingen: Narr. 17-35.

Böttger, C. \& Probst, J. 2000. Adressatenorientierung in englischen und deutschen Texten. Working Papers in Multilingualism, Series B, (23). Hamburg: Universität Hamburg.

Bührig, K. \& Rehbein, J. 2000. Reproduzierendes Handeln. Übersetzen, simultanes und konsekutives Dolmetschen im diskursanalytischen Vergleich. Working Papers in Multilingualism, Series B, (6). Hamburg: Universität Hamburg.

Bußmann, H. 1990. Lexikon der Sprachwissenschaft. Stuttgart: Kröner.

Clark, H. 1992. Arenas of Language Use. University of Chicago Press: Chicago.

Dale, R. 1992. Exploring the Role of Punctuation in the Signalling of Discourse Structure. In: Proceedings of a Workshop on Text Representation and Domain Modelling. Berlin: Technical University of Berlin.

Doherty, M. 1995. Prinzipien und Parameter als Grundlagen einer allgemeinen Theorie der vergleichenden Stilistik. In: Stickel, G. (ed.) Stilfragen. Berlin, New York: de Gruyter. 181197.

Doherty, M. 2002. Language Processing in Discourse: A Key to Felicitous Translation. London, New York: Routledge.

Doran, C. 1998. Incorporating Punctuation into the Sentence Grammar: A Lexicalized Tree Adjoining Grammar Perspective. PhD thesis, University of Pennsylvania.

Englund-Dimitrova, B. 2005. Expertise and Explicitation in the Translation Process. Amsterdam: Benjamins.

Englund-Dimitrova, B. 1993. Semantic Change in Translation - A Cognitive Perspective. In: Gambier, Y. \& Tommola, J. (eds.) Translation and Knowledge. Turku: Centre for Translation and Interpreting, University of Turku. 285-296.

Fabricius-Hansen, C. 1996. Informational Density - A Problem for Translation and Translation Theory. Linguistics Vol. 34. 521-565.

Fabricius-Hansen, C. 1998. Informational Density and Translation, with Special Reference to German Norwegian - English. In: Johannson, S. \& Oksefjell, S. (eds.) Corpora and Crosslinguistic Research. Theory, Method, and Case Studies. Amsterdam: Rodopi. 197-234.

Fabricius-Hansen, C. 1999. Information Packaging and Translation: Aspects of Translational Sentence Splitting (German - English/Norwegian). In: Doherty, M. (ed.) Sprachspezifische Aspekte der Informationsverteilung. Berlin: Akademie Verlag. 174-214.

Fabricius-Hansen, C. 2005. Elusive Connectives. A Case Study on the Explicitness Dimension of Discourse Coherence. Linguistics Vol. 43. No.1. 17-48.

Fairbairn, G. \& Winch, C. 1996. Reading, Writing and Reasoning. A Guide for Students. Buckingham: Open University Press.

Gallmann, P. 1985. Graphische Elemente der geschriebenen Sprache: Grundlagen für eine Reform der Orthographie. Tübingen: Niemeyer.

Gumul, E. 2006. Explicitation in Simultaneous Interpreting: A Strategy or a By-product of Language Mediation? Across Languages and Cultures Vol. 7. No. 2. 171-190.

Heltai, P. 2005. Explicitation, Redundancy, Ellipsis and Translation. In: Károly, K. \& Fóris Á. (eds.), New Trends in Translation Studies. In Honour of Kinga Klaudy. Budapest: Akadémiai Kiadó. 45-74. 
Hoffmann, L. 1998. Parenthesen. Linguistische Berichte No. 175. 299-328.

House, J. 1996. Contrastive Discourse Analysis and Misunderstanding: The Case of German and English. In: Hellinger, M. \& Ammon, U. (eds.) Contrastive Sociolinguistics. Berlin: Mouton de Gruyter. 345-361.

House, J. 1997. Translation Quality Assessment. A Model Revisited. Tübingen: Narr.

House, J. 2002. Maintenance and Convergence in Covert Translation English-German. In: Behrens, B., Fabricius-Hansen, C., Hasselgard, H. \& Johansson, S. (eds.) Information Structure in a Cross-Linguistic Perspective. Amsterdam: Rodopi. 199-211.

House, J. 2003. Misunderstanding in Intercultural University Encounters. In: House, J., Kasper, G. \& Ross, S. (eds.) Misunderstanding in Social Life. London: Pearson Longman. 22-56.

House, J. 2004. Explicitness in Discourse Across Languages. In: House, J., Koller. W. \& Schubert, K. (eds.) Neue Perspektiven in der Übersetzungs- und Dolmetschwissenschaft. Bochum: AKS. 185-208.

House, J. 2006. Text and Context in Translation. Journal of Pragmatics Vol. 38. No. 3. 338-358.

Kelletat, A. 1998. Eigennamen. In: Snell-Hornby. M. et al. (eds.) Handbuch Translation. Tübingen: Stauffenburg. 297f.

Klaudy, K. 1993. On Explicitation Hypothesis. In: Klaudy, K. \& Kohn, J. (eds.) Transferre Necesse Est ... Current Issues of Translation Theory. Szombathely: Dániel Berzsenyi College. 69-77.

Klaudy, K. 1998. Explicitation. In: Baker, M. \& Malmkjær, K. (eds.) Routledge Encyclopedia of Translation Studies. London: Routledge. 80-84.

Mason, I. 2006. On Mutual Accessibility of Contextual Assumptions in Dialogue Interpreting. Journal of Pragmatics Vol. 38. 359-373.

Meyer, C. F. 1987. A Linguistic Study of American Punctuation. New York: Peter Lang.

Monacelli, C. 2006. Implications of Translational Shifts in Interpreter-Mediated Events. Pragmatics Vol. 16. No. 4. 457-473.

Nerius, D. (ed.) 2000. Duden-Deutsche Orthographie. Mannheim: Bibliographisches Institut \& Brockhaus AG.

Nida, E. 1964. Toward a Science of Translating. Leiden: Brill.

Olohan, M. \& Baker, M. 2000. Reporting that in Translated English: Evidence for Subconscious Processes of Explicitation? Across Languages and Cultures Vol. 1. No. 2. 141-158.

Øverås, L. 1998. In Search of the Third Code. An Investigation of Norms in Literary Translation. Meta Vol. 43. No. 4. 571-590.

Pápai, V. 2004. Explicitation: a Universal of Translated Text? In: Mauranen, A. \& Kujamäki, P. (eds.) Translational Universals: Do They Exist? Amsterdam: John Benjamins Publishing Co. 143-164.

Pöchhacker, F. 1994. Simultandolmetschen als komplexes Handeln. Tübingen: Narr.

Pöchhacker. F. 2004. Introducing Interpreting Studies. London: Routledge.

Puurtinen, T. 2004. Explicitation of Causal Relations: a Corpus-Based Analysis of Clause Connectives in Translated and Non-Translated Finnish Children's Literature. In: Mauranen, A. \& Kujamäki, P. (eds.) Translational Universals: Do They Exist? Amsterdam: Benjamins. $165-176$.

Quirk, R., Greenbaum, S., Leech, G. \& Svartvik, J. 1985. A Comprehensive Grammar of the English Language. London, New York: Longman.

Schmied, J. \& Schäffler, H. 1997. Explicitness as a Universal Feature of Translation. In: Ljung, M. (ed.): Corpus-based Studies in English. Papers from the Seventeenth International Conference on English Language Research on Computerized Corpora (ICAME 17), Stockholm, May 15-19, 1996. Amsterdam: Rodopi. 21-34.

Schneider, S. 2007. Reduced Parenthetical Clauses as Mitigators: a Corpus Study of Spoken French, Italian, and Spanish. Amsterdam: John Benjamins. 
Searle, J. 1975. Indirect Speech Acts. In: Cole, P. \& Morgan, J. (eds.) Syntax and Semantics Volume 3: Speech Acts. New York: Academic Press. 59-82.

Séguinot, C. 1988. Pragmatics and the Explicitation Hypothesis. TTR Traduction, Terminologie, Rédaction Vol. 1. No. 2. 106-114.

Setton, R. 1999. Simultaneous Interpretation: a Cognitive-Pragmatic Analysis. Amsterdam: John Benjamins.

Setton, R. 2006. Context in Simultaneous Interpretation. Journal of Pragmatics Vol. 38, 374-389.

Stalnaker, R. (1978/2002). Assertion. Reprint in Portner, P. \& Partee, B. (eds.) Formal Semantics. The Essential Readings. Oxford: Blackwell Publishing. 147-161.

Steiner, E. 2004. Translated Texts: Properties, Variants, Evaluations. Frankfurt/Main: Peter Lang.

Steiner, E. 2005. Explicitation, its Lexicogrammatical Realization, and its Determining (independent) Variables - towards an Empirical and Corpus-based Methodology. SPRIKreports - Reports of the Project Languages in Contrast (Språk i contrast), No. 36. http://www.hf.uio.no/forskningsprosjekter/sprik

Steiner, E. (in press). Empirical Studies of Translations as a Mode of Language Contact "Explicitness" of Lexicogrammatical Encoding as a Relevant Dimension. In: Siemund, P. \& Kintana, N. (eds.) Language Contact and Contact Languages. Amsterdam: John Benjamins.

Thompson, S. 1978. Modern English from a Typological Point of View: Some Implications of the Function of Word Order. Linguistische Berichte Vol. 54. 19-35.

Tymoczyko, M. 1998. Computerized Corpora and Translation studies. Meta Vol. 43. No. 3. 652659.

v. Hahn, W. 1996. Das Postulat der Explizitheit für den Fachsprachengebrauch. In: Hoffman, L., Kalverkämper, H. \& Wiegand, H.E. (eds.) Fachsprachen. Languages for Special Purposes. An International Handbook of Special Languages and Terminology Research. New York: de Gruyter. 383-389.

v. Kügelgen, R. 2003. Parenthesen handlungstheoretisch betrachtet. In: Hoffmann, L. (ed.) Funktionale Syntax. Die pragmatische Perspektive. Berlin, New York: de Gruyter. 208230.

Vanderauwera, R. 1985. Dutch Novels Translated into English: The Transformation of a Minority Literature. Amsterdam: Rodopi.

Vianna, B. 2005. Simultaneous Interpreting: a Relevance-Theoretic Approach. Intercultural Pragmatics Vol. 2. No. 2. 169-190.

Vinay, J. P. \& Darbelnet, J. 1958/1977. Stylistique comparée du francais et de l'anglais. Méthode de traduction. Paris: Didier.

Wadensjö, C. 1998. Interpreting as Interaction. London: Longman.

Weissbrod, R. 1992. Explicitation in Translation of Prose Fiction from English into Hebrew as a Function of Norms. Multilingua Vol. 11. No. 2. 153-171.

Zifonun, G., Hoffmann, L. \& Strecker, B. (1997). Grammatik der deutschen Sprache. Berlin, New York: de Gruyter. 